\title{
A Case of Acute Flaccid Paralysis: An Uncommon Presentation of a Common Disease
}

\author{
Shrestha $\mathbf{S}^{1}$, Regmi SK ${ }^{2}$ \\ ${ }^{1}$ Dr. Shrijana Shrestha, MD Paediatrics, Associate Professor, ${ }^{2}$ Dr. Subodh Kr Regmi, MBBS, Department of Paediatrics, Patan \\ Hospital Kathmandu, Nepal
}

Address for Correspondence: Dr. Shrijana Shrestha

E-mail: shri_rishi@hotmail.com

\section{Case History}

An eleven year old girl from the periphery of Kathmandu valley presented to our hospital with the history of highgrade fever since the past twenty days, gradually progressive weakness of lower limbs since the last eight days and inability to stand or walk along with loss of bowel and bladder control for two days. There was no history of trauma, altered level of consciousness, skin or mucosal bleeds or any joint symptoms. She received some medications from the local heath post, details of which were not known. There was no significant past medical history and no known TB contacts. She was third of the six children in the family and was not immunized against any of the vaccine preventable diseases

On examination she was conscious, febrile, sick looking, pale and had generalized bony tenderness. Vitals were stable. Cranial nerves and sensations were intact. She had complete flaccid paralysis of the lower limbs with diminished but preserved knee jerks and bilateral up going planters. There was doubtful neck stiffness and no papilloedema. Other systemic examinations were normal.

Initial investigations showed normal total and differential counts. She had low Hematocrit (24\%) and the Platelet count was $(82,000 / \mathrm{cu} \mathrm{mm})$. Cerebrospinal fluid analysis showed WBC 35 with 45\% Polymorphs, Protein of $635 \mathrm{mg} / \mathrm{dl}$ and Sugar 44 mg/dl. Blood Sugar, Electrolytes, Creatinine, Chest and Spinal X-rays were all normal.

The differential diagnoses on admission were partially treated meningitis versus tubercular meningitis (TBM) but neither of them did clearly explain the paraparesis. Besides, to diagnose TBM, an intact sensorium in the presence of neurological deficits is unlikely. Systemic malignancies and GB syndrome were considered lower down on the list of differential diagnosis. Further investigation showed ESR of $80 \mathrm{~mm} / \mathrm{hr}$, strongly positive Mantoux, 5\% blasts in the peripheral smear and bone marrow aspiration showed $90 \%$ blasts. MRI of the spine revealed proteinaceous fluid (blood or blood mixed exudates) in the extradural space with spinal cord compression at upper thoracic region.

The final diagnosis was acute leukaemia with paraparesis due to spinal compression and extradural bleed. The strongly positive mantoux most probably was due to activation of occult TB with the immunocompromised state because of leukaemia. She was then referred to the Oncology unit for further management.
Figure I: MRI showing proteinaceous fluid in extradural space at upper thoracic spine

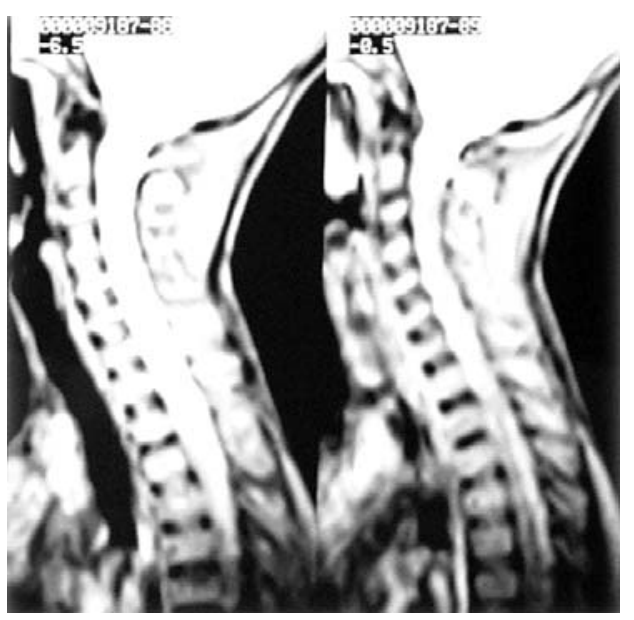

\section{Discussion}

Among the childhood systemic malignancies initially presenting with neurological features, acute leukaemia is the most common one ${ }^{1}$. In acute leukaemias, neurological features can present as meningeal, orbital or cerebellar infiltrates. It may present with back pain, weakness and difficulty walking due to anaemia, or bone pain. Occasionally it could be due to bleeds and rarely with epidural spinal cord compression. Bone pain in acute leukaemia is due to marrow expansion and is mediated through the periosteal pressure sensitive nerve endings and deep somatic nociceptors. It is a diffuse aching type of pain and is less localized. Non-articular bone pain is suggestive of systemic malignancy rather than rheumatological disorder ${ }^{2}$. A large subset of patients with childhood leukaemia can present with bone pain as an initial symptom in association with nearly normal hematological indexes ${ }^{3}$.

\section{References}

1. Aysun S, Topcu M, Gunay M \& Topaloglu H. Neurological Features As Initial Presentations of Childhood Malignancies. Pediatr Neurol.1994;10(1): 40-43.

2. Cabral DA, Tucker LB. Malignancies In Children Who Initially Present With Rheumatic Complains. J Pediatr. 1999; 134: 53-57.

3. Jonsson OG, Sartain P, Ducore JM, et al. Bone Pain As An Initial Symptom of Childhood Acute Lymphoblastic Leukemia: Association With Nearly Normal Hematological Indexes. J Pediatr. 1990;117: 233-237. 